\title{
An Analysis of Online Classes Tweets Using Gephi: Inputs for Online Learning
}

\author{
Joje Mar P. Sanchez, Blanca A. Alejandro, Michelle Mae J. Olvido, and Isidro Max V. Alejandro
}

\begin{abstract}
The conduct of online classes has emerged as one of the major changes in the educational landscape at the onset of COVID-19. Its implementation has been met by varying reactions that have become evident in social media, particularly on Twitter. This paper analyzed \#onlineclasses tweets of Filipino users using network analysis through Gephi and NodeXL software. The resulting network has 2,278 users and 998 interactions with many groups of small interactions among users, and low clustering coefficient and modularity values. The users in the top 8 communities in the network talk about the challenges brought about by online classes and the opportunities that online networks offer. Hence, the network of \#OnlineClasses tweets can be described as a community cluster. Smaller groups of users who engaged in aspects of online classes emerge in the network, signifying that Filipinos have differing points of view about the topic. Sentiment sharing through social networks provides an avenue for sharing challenges and building communities that help address challenges for online learning in the pandemic.
\end{abstract}

Index Terms-Online classes, tweets, network analysis, Gephi, online learning.

\section{INTRODUCTION}

The Coronavirus Disease 2019 (COVID-19) pandemic has triggered unprecedented changes in all sectors of society, including education. In the ongoing challenge of the said health crisis, the transition to online learning has emerged as an unavoidable option [1]. However, online learning has come with challenges as the realities of the digital divide and lack of access to devices, internet connections, and necessary accommodations for learners have come up [2], especially among school children who are deemed vulnerable [3].

An online class is a course conducted over the Internet. It is generally conducted through a learning management system, in which students can view their course syllabus and academic progress, as well as communicate with fellow students and their course instructor. Considering the possibilities brought about by access to the internet, the exchange of information and sentiments over the world wide web can influence the education of students as the school community widens. This is most evident in discussions over

Manuscript received June 22, 2021; revised June 28, 2021.

J. M. Sanchez and M. M. Olvido are with the Professional Education Department, College of Teacher Education, Cebu Normal University, Cebu City, 6000, Philippines (e-mail: sanchezj@cnu.edu.ph, olvidom@cnu.edu.ph).

B. Alejandro is with the Integrated Laboratory School, College of Teacher Education, Cebu Normal University, Cebu City, 6000, Philippines (e-mail: alejandrob@cnu.edu.ph).

I. M. Alejandro is with the College of Teacher Education, and Center for Innovative Flexible Learning, Cebu Normal University, Cebu City, 6000, Philippines (e-mail: alejandroi@cnu.edu.ph). social network sites.

Social network sites (SNSs) like Twitter are increasingly attracting the attention of academic and industry researchers for having attracted millions of users, many of whom have integrated these sites into their daily practice [4]. Social networks, consisting mostly of young people as users, are highly informal environments that play a vital role in continuing the interaction outside the classroom. While it is expected that there is an increased interaction in social networks related to formal education, young people also use these applications to learn outside the virtual classroom by commenting on academic and social issues, dilemmas, and disappointments faced while pursuing university education [5]. In the paper of Nochumson [6], it is opined that Twitter may hold value as a legitimate platform for continuous teacher learning in the area of informing classroom teaching practices.

Social media is a computer-based technology that facilitates the sharing of ideas, thoughts, and information through the building of virtual networks and communities. By design, social media is internet-based and gives users quick electronic communication of content. Content includes personal information, documents, videos, and photos. Users engage with social media via computer, tablet, or smartphone via web-based software or web application, often utilizing it for messaging. The power of social media is the ability to connect and share information with anyone on Earth or with many people simultaneously [7].

Using social media initiates different topics online. It also deals with issues on current events, which can be political, educational, or personal. These will lead one to show their sentiments on every topic they consider relevant. The online sentiment is the emotion that people feel when engaging with your brand, product, or service [8]. It also extends to the opinions of users towards people, places, things, or events that they want to share with the community of users in their platform of choice. Specifically for this study, a focus on sentiments of users with regards to the conduct of online classes is investigated.

Using a large amount of data collected from Twitter yields an in-depth comparison of three measures of influence: indegree, retweets, and mentions [9]. Based on these measures, an investigation on the dynamics of user influence across topics and time. Observations were; first, popular users who have high indegree are not necessarily influential in terms of spawning retweets or mentions. Second, most influential users can hold significant influence over a variety of topics. Third, influence is not gained spontaneously or accidentally, but through concerted effort such as limiting tweets to a single topic. The researchers believe that these findings provide new insights for viral marketing and suggest 
that topological measures such as indegree alone reveals very little about the influence of a user. This may be a good basis for finding the influence of Twitter in education sector. These may help in gathering the information necessary for the improvement of institutions' online classes delivery.

In the Philippines, the implementation of online classes has been met by varying reactions, which have become evident in social media. The \#AcademicFreezeNow became the top trending topic on September 3, 2020, as colleges around the country opened the school year [10]. This reveals that sentiments towards the implementation of online classes are widely discussed over social media sites like Twitter. Trending topics on Twitter provide a picture of the information-sharing behaviors of people and, the interaction between users creates a network that influences the formation of beliefs.

Prior to the pandemic, various studies have indicated that social network analysis can be particularly effective in studying students' interactions in online collaboration [11] especially in light of the increased use of social media over time. It is important to note however that Social Network Analysis (SNA) is not limited to online connections. The said analysis have also been used to study the networks and relational structures of research topics in academic fields [12], look into social networks built by educational gamification [13] and explore learning relationships form in undergraduate classrooms, as well as the impacts these relationships have on learning outcomes [14]. The researchers tapped into the potential for SNA to reveal valuable insights on sentiments over the implementation of online classes.

Social media offers several opportunities in the classroom that include increased student engagement, building students' professional and peer networks, and developing their social media skills [15]. At the onset of mandatory online learning to alleviate the risks brought about by face to face classes, there is a need to investigate the social media influence of the students. This study uses text mining techniques mainly, a network analysis of tweets using \#onlineclasses using NodeXL and Gephi. In the study of Jun [16], the result shows that Gephi, which with powerful visualization function and stronger dynamic analysis, is more suitable for handling the dynamic big data for observability analysis.

Looking into the characteristics of social media influences in the Twitter networks on the discussion of online classes can provide valuable inputs for educators in the implementation of online learning.

\section{MATERIALS AND MethodS}

The study employed text mining analysis, a design that adopts the concepts of natural language processing with machine learning, data mining and knowledge management [17], [18]. This analysis was used to explore patterns from unstructured data coming from Filipino's tweets about online classes. The tweets were collected from Filipino users who tweeted or retweeted the hashtag \#OnlineClasses using NodeXL software (version 1.0.1.418). This software is built to process data from social media platforms such as extraction, analysis and visualization [19]. Rich data can be extracted using this software, including the user, tweets, mentions, replies, tweet date, language, source device, followed/follower, favorites, description, and location [20]. After data extraction, the data were cleaned by including only the crucial data for the study and removing irrelevant data [21].

After pre-processing and data cleaning, the data were subjected to social network analysis. This kind of network analysis can describe human relations using the concepts of graph theory, where human beings are visualized as nodes or vertices, and their interactions or relationships as edges or links [22]-[24]. In this study, the network analysis was conducted using the software called Gephi (0.9.2 licensed under the dual license CDDL and GNU General Public License version 3, C2008-2017). This software visualizes and analyzes networks in order to reveal trends and unveil stories with the data [25]. In this study, the nodes are the Twitter users and the edges are the retweets being received by the user, serving as their interactions with other users. Since Twitter follows an asymmetrical relationship (i.e., you may be followed but not necessary you will follow back) [26], a directed graph will be used [27]. The layout of the resulting graph was changed to Force Atlas 2 using the information in Table I [28].

TABLE I: FORCE ATLAS 2 ALGORITHM USED IN THE STUDY

\begin{tabular}{lll}
\hline \hline Thread & Threads number & 7 \\
\hline \multirow{3}{*}{ Performance } & Tolerance (speed) & 1.0 \\
& $\begin{array}{l}\text { Approximate repulsion } \\
\text { Approximation }\end{array}$ & 1.2 \\
\hline \multirow{3}{*}{ Tuning } & Scaling & 1800.00 \\
& Stronger gravity & \\
& Gravity & 1.0 \\
\hline \multirow{3}{*}{ Behavior } & Dissuade hubs & $\square$ \\
Alternatives & LinLog mode & $\square$ \\
& Prevent overlap & $\square$ \\
& Edge weight influence & 1.0 \\
\hline \hline
\end{tabular}

Network centrality (degrees, closeness, betweenness, Eigenvector) and modularity were run by the Gephi software and applied to the network following the process in the read literature [22], [28], [29]. The resulting network was analyzed for trends and data stories through the visualized outcomes of the network analysis.

\section{RESUlTS AND DisCUSSIONS}

\section{A. Statistical Descriptions}

The network of \#onlineclasses tweets among Filipino users is seen in Fig. 1.

Results of the Gephi run of the \#onlineclasses tweets present 2,278 nodes and 998 edges, indicating that there are 2,278 users who retweeted, mentioned and replied to in relation to the said hashtag and around 998 interactions are detected among these users. Using this context, centrality measures were calculated and graphed as shown in Fig. 2.

The average degree of the network is 0.438 ; this means that each user is interacting with essentially no other user on average. However, this does not mean that no interactions happened, but there are a lot of users whose tweets are not 
retweeted, mentioned or replied to. This is in fact supported by the degree distribution of the network that presents four users with a grade higher than 20 . This suggests that there are only a few users with many interactions while most of the users have few interactions with other users. Moreover, the in-degree distribution characterizes the users having the grade 20 and higher have more followers than the rest of the users in the network, with approximately 64 followers being the highest following to one user. Furthermore, the out-degree distribution shows that the minority (users with more followers) has 5-9 followers while the majority (those with less followers) mostly has 3 followers.

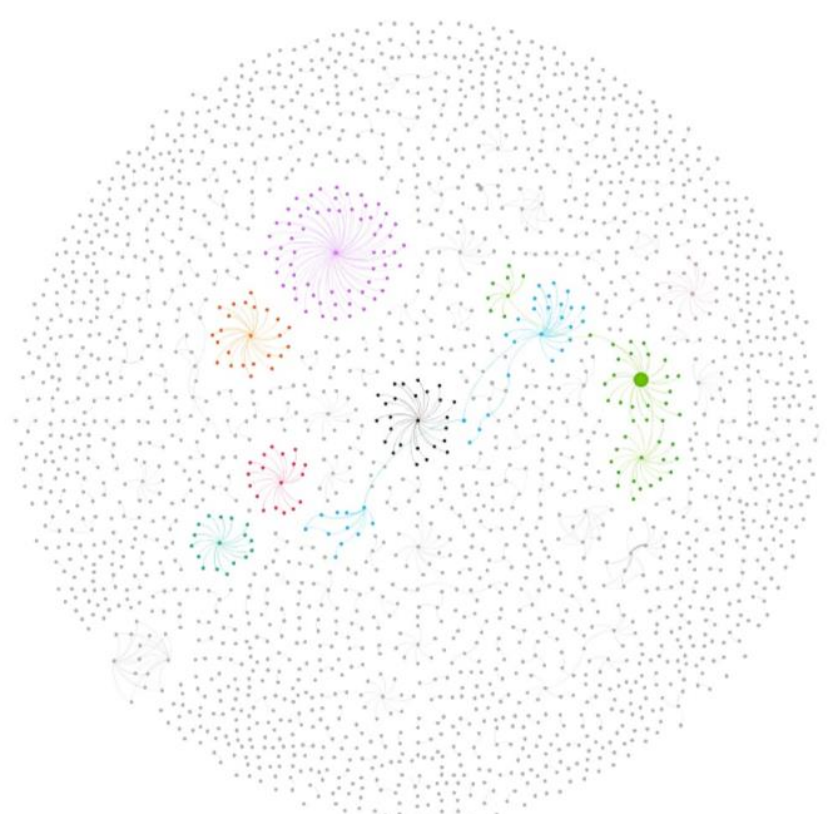

Fig. 1. Network of \#OnlineClass tweets

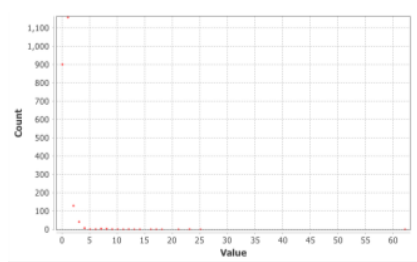

(a) Degree/In-degree distribution

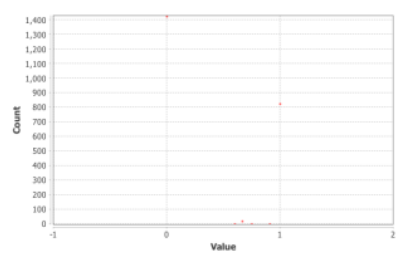

(c) Closeness centrality distribution

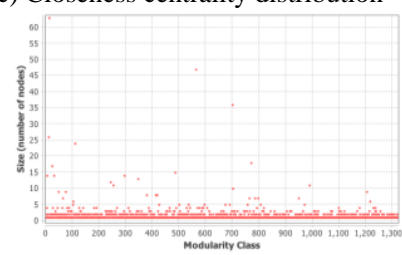

(e) Modularity distribution

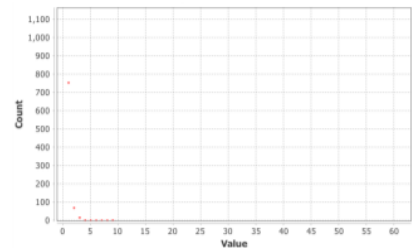

(b) Out-degree distribution

s

d) Clustering coefficient distribution distribution

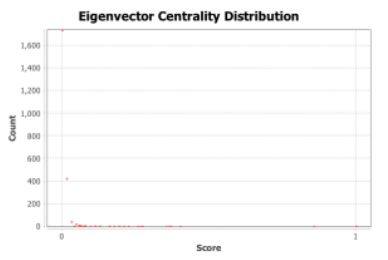

(f) Eigenvector centrality distribution

Fig. 2. Statistical descriptions derived from Gephi network analysis

The maximum distance between two users of the network is 2 while the average distance between them is 1.023 . To put in context, the closeness centrality distribution puts about 1,400 users very far from the center of the network whereas, approximately 820 users are located at the center of the network. The rest of the users are found surrounding that center. Around 1324 weakly connected components and 2275 strongly connected components are found in the network. This means that there are 1,324 related components, and the giant component groups 2,275 users. A clustering coefficient of 0.006 is derived from the analysis, suggesting that most of the users have hardly connections with their neighborhood.

As a very low clustering coefficient is accounted, the network has high modularity value equal to 0.987 . Because of this, there are around 1,324 communities in the network. The top eight communities have at most 63 users $(2.77 \%)$ and at least 15 users $(0.66 \%)$. The rest of the communities are smaller clusters while others are isolated users who have not interacted with others. Lastly, the eigenvector centrality is calculated at 0.019 . This very low value means that the users are rarely interacting with the central users of the community and other communities in the network.

\section{B. Characteristics of the Influential Users in the Communities}

The Gephi results highlight eight communities. These communities have influential users who act as the primary node of the edges in such modularities. The characteristics of these users are showcased in Table II below.

TABLE II: SOME CHARACTERISTICS OF THE INFLUENTIAL USERS IN THE TOP EIGHT COMMUNITIES

\begin{tabular}{|c|c|c|c|c|c|c|c|}
\hline $\begin{array}{l}\text { User } \\
\text { Code }\end{array}$ & $\begin{array}{l}\text { Acct. } \\
\text { Type }\end{array}$ & Age & Work & Locale & $\begin{array}{l}\text { Year } \\
\text { joined }\end{array}$ & $\begin{array}{l}\text { Follow } \\
\text {-ing }\end{array}$ & $\begin{array}{l}\text { Follow } \\
\text {-ers }\end{array}$ \\
\hline A1 & Personal & 18 & $\begin{array}{c}\text { Stude } \\
\text { nt }\end{array}$ & $\begin{array}{l}\text { Phils./ } \\
\text { Korea }\end{array}$ & 2018 & 3,556 & 8,089 \\
\hline B1 & Personal & -- & $\begin{array}{c}\text { Stude } \\
\text { nt }\end{array}$ & Phils. & 2019 & 1,464 & 1,242 \\
\hline $\mathrm{C} 1$ & Personal & -- & $\begin{array}{c}\text { Stude } \\
\text { nt }\end{array}$ & $\begin{array}{l}\text { Phils./ } \\
\text { China }\end{array}$ & 2018 & 6,161 & 31,300 \\
\hline D1 & Business & 23 & $\begin{array}{l}\text { Busi } \\
\text { ness }\end{array}$ & Phils. & 2015 & 248 & 726 \\
\hline E1 & Personal & 20 & Artist & Phils. & 2019 & 62 & 3,421 \\
\hline F1 & Personal & -- & Artist & $\begin{array}{c}\text { Phils./ } \\
\text { USA }\end{array}$ & 2011 & 1,328 & $\begin{array}{c}120,20 \\
0\end{array}$ \\
\hline G1 & Personal & -- & $\begin{array}{c}\text { Stude } \\
\text { nt }\end{array}$ & Phils. & 2015 & 6,504 & 10,400 \\
\hline H1 & Fan & -- & Fan & $\begin{array}{l}\text { Phils./ } \\
\text { Korea }\end{array}$ & 2020 & 56 & 2,133 \\
\hline
\end{tabular}

Based on Table II, most of the influential users make use of their Twitter accounts for personal purposes (75\%), while one use it for business while the other as a fan account. Although most of the ages are not indicated, the influential users are most likely to be in their late adolescence to early adulthood stages (18-23 years old). This age estimation is verified by their occupation as most of them are students $(62.5 \%)$ whereas, others are into business, the arts, and fan voting. All of the influential users identified themselves to be located in the Philippines, while four users (50\%) indicated that they also live in USA and eastern Asian countries.

Additionally, the influential users joined the tweeting community as early as $2011(12.5 \%)$ and as recent as 2020 $(12.5 \%)$. In terms of following other users, most of influential users $(62.5 \%)$ do this in at least 1,300 times and some $(37.5 \%)$ follow less than 250 other users. All but one influencer have a number of followers greater than 1,200; the user with the least number of followers only has 726 followers even though the account was created last 2015 and intended for business purposes. Therefore, most of the 
influencers joined the community in 2018-2019, have followed other users more than a thousand times, and are followed by at least 1,200 users.

\section{Descriptions of the Top Communities}

The communities in the network can be described through qualitative examination of the community itself and the tweet of the influential user that binds and forms such community (Table III).

TABLE III: DESCRIPTIONS OF THE TOP 8 COMMUNITIES IN THE NETWORK

\begin{tabular}{|c|c|c|c|c|}
\hline Community & Visualization & Main Users & $\begin{array}{l}\text { No. of } \\
\text { Edges }\end{array}$ & Main Idea \\
\hline A & & A1 & 63 & $\begin{array}{l}\text { Negative impact } \\
\text { to mental health }\end{array}$ \\
\hline B & $\bullet$ & $\begin{array}{l}\text { B1 } \\
\text { B2 } \\
\text { B3 } \\
\text { B4 } \\
\text { B5 } \\
\text { B6 }\end{array}$ & $\begin{array}{c}22 \\
2 \\
7 \\
2 \\
2 \\
17\end{array}$ & $\begin{array}{l}\text { Asking of } \\
\text { donations for } \\
\text { the lack of } \\
\text { online } \\
\text { equipment }\end{array}$ \\
\hline $\mathrm{C}$ & & $\begin{array}{c}\mathrm{C} 1 \\
\mathrm{C} 2 \\
\mathrm{C} 3 \\
\mathrm{C} 4 \\
\mathrm{C} 5 \\
\mathrm{C} 6 \\
\mathrm{C} 7 \\
\mathrm{C} 8 \\
\mathrm{C} 9 \\
\mathrm{C} 10\end{array}$ & $\begin{array}{c}21 \\
2 \\
2 \\
2 \\
2 \\
9 \\
2 \\
2 \\
2 \\
2\end{array}$ & $\begin{array}{l}\text { Stress brought } \\
\text { about by online } \\
\text { classes }\end{array}$ \\
\hline D & $\because$ & D1 & 26 & $\begin{array}{l}\text { Selling of } \\
\text { products to buy } \\
\text { gadgets for } \\
\text { online classes }\end{array}$ \\
\hline E & $\because$ & E1 & 24 & $\begin{array}{l}\text { Lagging of } \\
\text { online classes } \\
\text { due to bad } \\
\text { Internet }\end{array}$ \\
\hline $\mathrm{F}$ & $\therefore \quad \because$ & $\mathrm{F} 1$ & 18 & $\begin{array}{l}\text { Being certified } \\
\text { (of a course) } \\
\text { online }\end{array}$ \\
\hline G & $\because \quad$. & G1 & 17 & $\begin{array}{l}\text { Difficulty in } \\
\text { online classes }\end{array}$ \\
\hline $\mathrm{H}$ & $\therefore \circ$ & H1 & 15 & $\begin{array}{l}\text { Delaying of } \\
\text { polls due to } \\
\text { attendance in } \\
\text { online classes }\end{array}$ \\
\hline
\end{tabular}

Two types of communities have been observed in the network, namely non-branching communities and branching communities. Non-branching communities dominate in the network $(75 \%)$ with an influential user at the center. The influencer tweeted about \#onlineclasses, which the other users retweeted, mentioned and replied to, signifying a directed path towards the influencer. However, none of the retweets, mentions or replies had interactions with other users, making the communities non-branching. Community A has the most interactions (63), followed by D (26), E (24), F (18), G (17), and the least, H (15). On the other hand, there are two communities that are branching $(25 \%)$. The user's retweet, mention or reply was shared by other users that created branches in the community, such as the case of communities B (47 interactions) and C (36 interactions).

Tweets by the influencers in the non-branching communities were content analyzed. Most of these tweets revolve around the challenging consequences of online class while two tweets talk about opportunities for online classes and a tweet about delayed polling due to attendance in online classes. Branching communities also have the same ideas as those of non-branching ones. The tweets in these communities have one challenge and one opportunity. With these ideas coming from the influencer's tweets, two themes are derived: (1) Online classes are challenging to the students, and (2) Online classes denote opportunities.

\section{1) Online classes are challenging to the students}

Most of the communities are characterized by sharing tweets related to the challenges brought about by online classes. The biggest communities, A and B talk about the negative impact of online classes to the students' mental health. The influencer A1 also points out to home quarantines that started issues on their mental health and online classes added more weight on the issues. B2 states the stress that has gotten on him when online classes started. Anxiety and stress are the common mental health issues among students during such classes. Moreover, community E's sharing is all about how bad Internet connection has affected their learning during online classes. User E1illustrates how his professor was lagging, leading him to edit anime characters in his computer. Dead airs exist during online classes that may lead to students' disinterest to the subject matter and the course itself. Furthermore, community $\mathrm{F}$ retweets and mentions about difficulty encountered during online classes. The influential user, in all of his honesty, highlights how online classes make learning even harder than the physical face-to-face instruction. Mental health, online learning, and characteristic difficulty of online classes are the challenges shared by the communities in the social network [30].

\section{2) Online networks offer opportunities}

Not all communities talk about the challenging aspects of online classes. In fact, three communities are characterized to have tweets centered on the opportunities that arise due to online classes. Influential users B1 and D1 use tweets as opportunities to ask donations or sell products to buy materials and equipment important in the conduct of online classes. Their communities shared these tweets in order to help the influencers to acquire the needed online gadgets. The nature of their communities signify that there are a lot of Filipino students needing online class resources and there are many people willing to help these students in order to continue learning amidst the crisis of times. Aside from this, the community of influencer F1 shared that opportunity for one's certification can happen online. He iterates that to be certified online, one has to attend online classes. Online classes offer opportunities to be informed about the condition of students and help them in one way and another, and to be 
certified online given attendance to online classes.

\section{Characterizing the Topic Network Produced}

The topic network in Fig. 3 shows that there are communities of users, and isolated users.

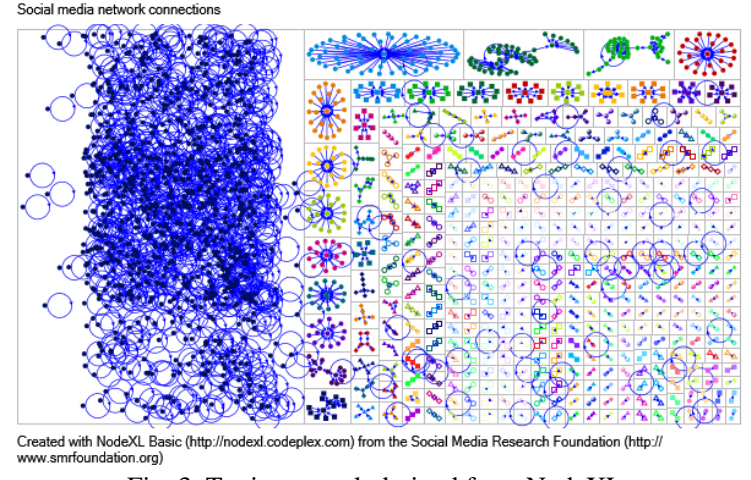

Fig. 3. Topic network derived from NodeXL.

In this network, there is a high proportion of users in communities and slightly less isolates in the network. This means that there are many users who engaged with other users in the network, while there are also those who do not have any engagement at all. Himelboim et al. [31] calls this topic network as clustered networks or community clusters.

Community clusters are characterized by an emergence of many small communities alongside a lower fraction of isolated users. Such networks often talk about recent topics that have many points of view. In online classes network, Twitter users talk about the possible and actual consequences of online classes brought about by the new normal of education. Since users have different points of view about these classes, there are many smaller groups of users who engage on certain view, and few bigger groups and less isolated users. These points of view are mostly disconnected from other points of view may be due to different realities and socio-economic status in the society. Due to disconnections among groups of users, there are many centers of topic engagement. Each center has its own influencer(s), audience and information sources.

Ultimately, the cluster network derived from online classes tweet engagements indicate that the topic has attracted spontaneous conversations among different groups of individuals such as students, artists, businessmen and even voting polls. Each of online classes conversations ignite multiple points of view, and this reflects diversity of opinion on the subject matter. Hence, Filipino users are divided when it comes to their opinions and experiences about online classes.

\section{CONCLUSION AND RECOMMENDATIONS}

The network of \#OnlineClasses tweets can be described as a community cluster. Smaller groups of users who engaged in aspects of online classes emerge in the network, signifying that Filipinos have differing points of view about the topic. Sentiment sharing through social networks provides an avenue for sharing challenges and building communities that help address challenges for online learning in the pandemic.

The results of the Gephi and NodeXL network analysis provide insights of how users, mostly students, perceive online classes and how they have experienced this new mode of learning. Examination of the network led the researchers to formulate three policy recommendations as follows:

\section{A. Provision of Psychosocial and Technical Support for Students}

A team of IT experts, guidance counselors, and staff of offices should be accessible to students to answer queries or address their need to be listened to as they deal with the challenges of online learning. Trained personnel and faculty should be made available to support students for psychosocial and technical support. The educational institution should invest in training the support team so that they can provide adequate assistance to students and employees.

\section{B. Capacitation of Students and Faculty for the Learning Modality for Implementation or the Adoption of a Learning Modality to the Capacity of the Students and Faculty to Implement}

Prior to the implementation of a learning modality, educational institutions should ensure that students and faculty have the skills and necessary resources to implement teaching and learning activities. This may include but not limited to the training of the use of the learning management system and the provision of gadgets and modules whichever is applicable. Should the institution be unable to provide the needed gadgets for online learning, the learning modality for distance learning should be adjusted to what students and faculty are able to implement.

C. Creation of a System of Monitoring and Evaluation of the Implementation of Online Learning and the Provision of Intervention When Necessary

Considering the multifaceted challenges brought about by the pandemic, educational institutions must continuously monitor the implementation of online learning and provide a mechanism for evaluation and adoption of an intervention whenever necessary. The COVID-19 pandemic has brought about unprecedented times and no one can claim full readiness.

\section{CONFLICT OF INTEREST}

The authors declare no conflict of interest.

\section{AUTHOR CONTRIBUTIONS}

J.M. Sanchez and M.M. Olvido conceptualized the paper; J.M. Sanchez and I.M. Alejandro did the methodology and software manipulation; J.M. Sanchez, B. Alejandro, M.M. Olvido, and I.M. Alejandro analyzed the data and visualized the results; J.M. Sanchez, B. Alejandro, and M.M. Olvido wrote the original draft; and M.M. Olvido reviewed and edited the paper. All authors have read and agreed to the published version of the manuscript.

\section{ACKNOWLEDGMENT}

The authors would like to extend their gratitude to the Center of Research and Development of Cebu Normal University for the training on Gephi analysis, and to the late 
Dr. Roberto N. Padua, former Higher Education Commissioner, for his expertise and research commitment that led to the conceptualization and writing of this paper.

\section{REFERENCES}

[1] W. Bao, "COVID-19 and online teaching in higher education: A case study of Peking University," Human Behavior and Emerging Technologies, vol. 2, no. 2, pp. 113-115, Apr. 2020

[2] L. Archambault and J. Borup, "Coming together as a research community to support educators and students in K-12 online and emergency remote settings," Journal of Online Learning Research, vol 6, no. 1, pp. 1-3, May 2020

[3] E. J. Sinteman, "E-Learning and Smart Revision Portal for Zambian primary and secondary school learners: A digitalized virtual classroom in the COVID-19 era and beyond," Aquademia, vol. 4, no. 2, May 2020

[4] D. M. Boyd and N. B. Ellison, "Social network sites: Definition, history, and scholarship," Journal of Computer-Mediated Communication, vol. 13, no. 1, pp. 210-230, Oct. 2007

[5] N. Selwyn. (Nov. 2007). Screw blackboard. Do it on Facebook! An investigation of students' educational use of Facebook. [Online] Available:

http://www.scribd.com/doc/513958/Facebookseminar-paper-Selwyn

[6] T. C. Nochumson, "Elementary schoolteachers' use of Twitter: Exploring the implications of learning through online social media," Professional Development in Education, vol. 46, no. 2, pp. 306-323, Mar. 2019

[7] M. Dollarhide. (Mar. 2021). Social media. Investopedia. [Online]. Available: https://www.investopedia.com/terms/s/social-media.asp

[8] B. Schaer. (Nov. 2020). What is online sentiment and how is it measured? Reputation $X$. [Online]. Available: https://blog.reputationx.com/measure-online-sentiment

[9] M. Cha, H. Haddadi, F. Benevenuto, and K. Gummadi, "Measuring user influence in twitter: The million follower fallacy," Fourth International AAAI Conference on Weblogs and Social Media, vol. 4 no. 1 , pp. 10-17, 2010

[10] G. Jopillo. (Sept. 2020). College students share remote learning woes as classes shift online. Rappler. [Online]. Available: https://www.rappler.com/nation/students-share-remote-learning-woesclasses-shift-online-pandemic

[11] M. Saqr, U. Fors, M. Tedre, and J. Nouri, "How social network analysis can be used to monitor online collaborative learning and guide an informed intervention," PloS One, vol. 13, no. 3, Mar. 2018

[12] Y. A. Ji, S. J. Nam, H. G. Kim, J. Lee, and S. K. Lee, "Research topics and trends in medical education by social network analysis," $B M C$ Medical Education, vol. 18, no. 1, pp. 1-10, Sept. 2018

[13] L. De-Marcos, E. García-López, A. García-Cabot, J. A. Medina-Merodio, A. Domínguez, J. J. Martínez-Herráiz, and T. Diez-Folledo, "Social network analysis of a gamified e-learning course: Small-world phenomenon and network metrics as predictors of academic performance," Computers in Human Behavior, vol. 60, pp. 312-321, Jul. 2016

[14] D. Z. Grunspan, B. L. Wiggins, and S. M. Goodreau, "Understanding classrooms through social network analysis: A primer for social network analysis in education research," CBE-Life Sciences Education, vol. 13, no. 2, pp. 167-178, Oct. 2017

[15] M. R. Dragseth, "Building student engagement through social media," Journal of Political Science Education, vol. 16, no. 2, pp. 243-256, Feb. 2019

[16] D. Jun. Comparative study of the social network analysis tools: Ucinet and Gephi. [Online]. Available: https://en.cnki.com.cn/Article_en/CJFDTotal-QBLL201408027.htm

[17] J. K. D. Treceńe, and R. J. P. Abides, "How did Twitter users react to the pandemic? Social network analysis of public tweets on CoViD-19 outbreak," Asia Pacific Journal of Multidisciplinary Research, vol. 8, no. 3, pp. 52-59, Aug. 2020

[18] M. Radovanović and M. Ivanović, "Text mining: Approaches and applications," Novi Sad Journal of Math, vol. 38, no. 3, pp. 227-234, 2008

[19] Pew Research Center. (2014). How we analyzed Twitter social media networks with NodeXL. [Online]. Available: https://www.pewresearch.org/wp-content/uploads/sites/9/2014/02/Ho w-we-analyzed-Twitter-social-media-networks.pdf

[20] Social Media Research Foundation. (2018). How to perform a Twitter social media brand analysis using NodeXL. NODE. [Online] Available:

https://nodexl.com/social-media-brand-analysis-guide-nodexl
[21] J. Han and M. Kamber, Data Mining: Concepts and Techniques (2nd Edition), San Francisco: Morgan Kaufmann Publishers, 2006.

[22] S. Wakid. (Aug. 2019). Case study: Cristiano Ronaldo's Twitter account network chain. [Online]. Available: https://medium.com/@syahrier.wakid/social-network-analysis-using-g ephi-cb4b2b0aa3b8

[23] M. Tsvetovat and A. Kouznetsov, Social Network Analysis for Startups: Finding Connections on the Social Web, O'Reilly Media, Inc., 2011

[24] A. J. O'Malley and P. V. Marsden, "The analysis of social networks," Health Services and Outcomes Research Methodology, vol. 8, pp. 222-26, Dec. 2008

[25] Gephi. (2017). About Gephi. [Online]. Available: https://gephi.org/about/

[26] R. I. M. Dunbar, V. Arnaboldi, M. Conti, and A. Passarella, "The structure of online social networks mirrors those in the offline world," Social Networks, vol. 43, pp. 39-47, Oct. 2015

[27] Autodesk. (2020). Gephi with Twitter data. Instructables Circuits. [Online]. https://www.instructables.com/id/Gephi-With-Twitter-Data/

[28] O. Anise and J. Wright. (Sept. 2018). Mapping social networks with Gephi. [Online]. Available: https://duo.com/blog/mapping-social-networks-with-gephi

[29] A. Alcalde. (Nov. 2018). An analysis and visualization of my twitter account with Gephi. The Programmer Chest. [Online]. Available: https://elbauldelprogramador.com/en/social-mining-gephi/

[30] S. Dhawan, "Online learning: A panacea in the time of COVID-19 crisis," Journal of Educational Technology, vol. 49, no. 1, pp. 5-22, Jun. 2020

[31] I. Himelboim, M. A. Smith, L. Rainie, B. Shneiderman, and C. Espina, "Classifying twitter topic-networks using social network analysis," Social Media + Society, pp. 1-13, Feb. 2017

Copyright (C) 2021 by the authors. This is an open access article distributed under the Creative Commons Attribution License which permits unrestricted use, distribution, and reproduction in any medium, provided the original work is properly cited (CC BY 4.0).

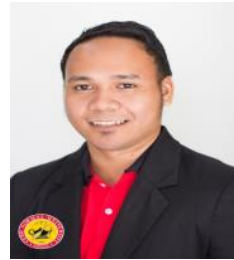

Joje Mar P. Sanchez earned his doctorate degree in science education at Cebu Normal University, Cebu City, Philippines. He got his master's degree in chemistry education from the University of the Philippines Cebu and baccalaureate degree in secondary education, major in physical sciences from Cebu Normal University, Cebu City

$\mathrm{He}$ is currently connected with the College of Teacher Education of Cebu Normal University. His research interests include chemistry and physics education, environmental education, educational data mining, and science investigatory project instruction.

Dr. Sanchez is a member of the Philippine Association of Chemistry Teachers (PACT), Samahang Pisika ng Pilipinas (SPP), Philippine Association for Teachers and Educators (PAFTE), among others.

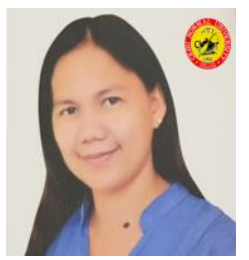

Blanca A. Alejandro earned her doctor of education in science education in Cebu Normal University. She earned her master of arts in teaching major in general science and bachelor of science in education major in biology in Central Mindanao University.

She is connected with the Integrated Laboratory School of the College of Teacher Education of Cebu Normal University, Cebu City. She teaches Student Teaching and different fields and areas of Sciences in the ILS and in the graduate school. She is the Research Chair coordinator of the ILS-CTE department.

Her research interests include Science pedagogy and innovative materials and teaching strategies. She also ventured on systematic reviews and phenomenological researches.

Dr. Alejandro is a member of Philippine Association for Teachers and Educators (PAFTE) and was given Presidential citation as an Outstanding faculty for consecutive years.

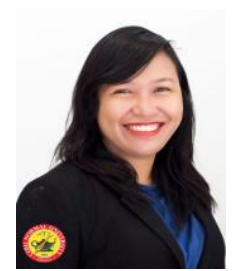

Michelle Mae J. Olvido earned her doctor of philosophy in education degree in research and evaluation, master of arts in education major in mathematics education and bachelor of elementary education - general education in Cebu Norma University.

She is connected with the College of Teacher Education of Cebu Normal University, Cebu City 
where she teaches research and statistics in the graduate level. Her research interests include research culture development, educational management, and teacher education. At present, she also serves as OIC Board and University Secretary and Executive Assistant

Dr. Olvido is a member of Philippine Association for Teachers and Educators (PAFTE), and associate member of the National Research Council of the Philippines (NRCP).

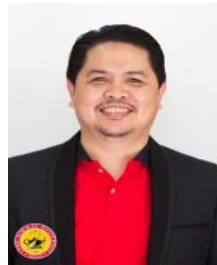

Isidro Max V. Alejandro is an EdD candidate at the University of Southern Philippines Foundation. He obtained his master's degree in Educational Management at the University of San Carlos, Cebu City and baccalaureate degree bachelor of science in education major in biology at Central Mindanao University, Bukidnon.

$\mathrm{He}$ is currently the administrator of the Center for
Innovative Flexible Learning (CIFL) of Cebu Normal University and is a faculty of the College of Teacher Education in the said university. His research interests include information and communications technology, ICT education, and Science education.

Mr. Alejandro is a member of Philippine Association for Teachers and Educators (PAFTE), among others. 